\title{
Molecular Microbiology Applied to the Study of Phytopathogenic Fungi
}

\author{
Carlos Garrido, Francisco J. Fernández-Acero, María Carbú, \\ Victoria E. González-Rodríguez, Eva Liñeiro, and Jesús M. Cantoral \\ Microbiology Laboratory, Faculty of Marine and Environmental Sciences \\ University of Cádiz, Puerto Real \\ Spain
}

\section{Introduction}

Fungi is an extensive group of eukaryotic microorganisms, generally they are microscopic and usually filamentous. It is estimated that there are between 70,000 and 1.5 millions species of fungi, most of them are being discovering and describing (Agrios, 2005). Most of the known hundred thousand fungal species are strictly saprophytic, living on decomposing dead organic matter. About fifty species cause disease in human, and more than ten thousand species can cause disease in one (obligate parasite) or many kinds of plants (nonobligate parasites) (Fernández-Acero et al., 2007a).

Phytopathogenic fungi are able to infect any tissue at any stage of plant growth. Plant pathogenic fungi show a complex life cycles, including both sexual and asexual reproduction stages (Agrios, 2005). Moreover, complex infection cycles and carbon assimilation is displayed (Garrido et al., 2010). These biological variability give them the possibility to develop its biological role from very climatologically different environments, since dry and desert zones until wet and hot regions in the tropic and equatorial area to the capacity to attack all plant tissues, from leaves to roots (Agrios, 2005).

During the last decades, the development of molecular methods has lead the Scientifics community to accumulate a high quantity of information from different molecular approaches (Fernández-Acero et al., 2011; Garrido et al., 2009b). Advances into Genomics, Transcriptomics, Proteomics, and more recently, Metabolomics are transforming research into fungal plant pathology, providing better and more accurate knowledge about the molecular biology and infection mechanisms showed by these fungi (Garrido et al., 2010).

Since 1992, our research group has been working with two of the most aggressive plant pathogens, which have been established such a model organisms for molecular and phytaphology studies: Botrytis cinerea and Colletotrichum acutatum (Fernández-Acero et al., 2006b, 2007a; Garrido et al., 2009b, 2010; Perfect et al., 1999). These genera include some of the most destructive plant pathogen species known. They induce worldwide diseases as, between others, the grey mould on grapes and the anthracnose on strawberries, respectively (Coley-Smith et al., 1980; Elad et al., 2004; Sutton, 1992). The losses caused by the phytopathogenic fungi Botrytis cinerea and Colletotrichum acutatum have been quantified 
between 10 and 100 million of Euros per year in Europe (Fernández-Acero et al., 2007a). Losses caused by B. cinerea in French vineyards oscillate between $15 \%$ and $40 \%$; in Holland, B. cinerea generates losses of about $20 \%$ of the flower crop; and, in Spain, the losses fluctuate between $20 \%$ and $25 \%$ of the strawberry crops (Fernández-Acero et al., 2007a). Colletotrichum spp. causes up to $80 \%$ plant death in nurseries and yield losses of $>50 \%$, being a major disease of cultivated strawberry (Denoyes-Rothan et al., 2004; Garrido et al., 2009a).

Our group has carried out an intense research activity of the molecular microbiology of these plant pathogens. These studies involve several molecular approaches in which the gel electrophoresis plays an important role. In this chapter, we will summarize the results obtained, and the molecular methods used for the study and characterization of the phytopathogen fungi Botrytis cinerea and Colletotrichum spp., all of them strongly related with different types of gel electrophoresis approaches and downstream protocols, including, between others, Pulse Field Gel Electrophoresis, agarose gel electrophoresis of DNA, Restriction Fragment Polymorphism Analyses, Southern-blot, Polyacrylamide Gel Electrophoresis and Two dimensional gel electrophoresis of proteins. These electrophoretic methods will be used to structure the development of chapter, describing the technical bases of each method and showing the approaches carried out and the results obtained.

\section{Chromosomal polymorphism and genome organization in Botrytis cinerea and Colletotrichum spp.}

Botrytis cinerea and Colletotrichum acutatum are two species of phytopathogenic fungi that show a very high level of phenotypic diversity among isolates. These fungi show complex cycles of life and infection, including both sexual and asexual forms (Garrido et al., 2008; Vallejo et al., 2002). Also high levels of somatic variability appear when the fungi are grown "in vitro", depending on the medium, temperature, light and other factors, which even determine differences in cultural characteristics, production of reproductive structures and pathogenicty between others (Bailey \& Jeger, 1992; Carbu, 2006; Garrido et al., 2009b; Rebordinos et al., 1997, 2000; Vallejo et al., 1996, 2001). These fungi do not show a high level of host specificity and they infect many different genera of hosts, adapting their infection strategy and metabolism to the environment conditions and kind of plant colonized. They are notoriously variable genera about which many fundamental questions relating to taxonomy, evolution, origin of variation, host specificity and mechanisms of pathogenesis remain to be answered (Bailey \& Jeger, 1992; Elad et al., 2004).

Many research projects are aimed to study the genome organization and chromosomal polymorphism trying to find the origin of phenotypic variability showed by these fungi. In the past decades, several strategies have been tested on lower fungi such as $B$. cinerea and Colletotrichum spp., i.e. cytological karyotyping, analysis of progeny from crosses between strains, sexual hybridizations, etc. These assays looked for a relation between molecular and phenotypic variability (Carbu, 2006; Faretra \& Antonacci, 1987; Faretra et al., 1988; Vallejo et al., 1996). Cytological studies showed a very high level of difficulty in this group of microorganisms due to small size and/or the difficulty to condense sufficiently the chromosomes to make them visible by microscope. These characteristics made difficult to obtain reliable information about the genome organization of these fungi, and the obtaining of conclusive results about their biological mechanisms of recombination and chromosomal polymorphisms. 
The development of Pulse- field gel electrophoresis (PFGE) resolved many problems found with cytogenetic studies in filamentous fungi. This technique has been widely used since the 90s for genomic characterization into fungal plant pathogens. PFGE allows the separation of large DNA molecules (DNAs from 100 bases to over 10 megabases (Mb) may be effectively resolved) which would all co-migrate in conventional agarose gels. This technique has proved to be a very useful tool to study aspects of genome organization in several yeast and fungi. It has led to the discovery that most species exhibit chromosome-length polymorphisms (CLPs), revealing a high level of intraspecific, and even population-level variability (Vallejo et al., 2002).

Technically, PFGE resolves chromosome-sized DNAs by alternating the electric field between spatially distinct pairs of electrodes. The electrophoresis cell consists of an array with 24 horizontal electrodes arranged in a hexagon. Agarose gels are electrophoresed horizontally, submerged under recirculated buffer. The system (CHEF-“Clamped Homogeneous Electric Field" and PACE "Programmable Autonomously Controlled Electrodes", from BIO-RAD) provides highly uniform, or homogenous, electric fields within the gel, using an array of 24 electrodes, which are held to intermediate potentials to eliminate lane distortion. Thus, lanes are straight. The system maintains uniform field using patented Dynamic Regulation. The electrodes sense changes in local buffer conductivity due to buffer breakdown, change in buffer type, gel thickness, or temperature, and potentials.

The preparation of samples for resolving chromosomal karyotypes by PFGE is not exempt of difficulty due to the biological characteristic of fungal cells. Fungus has to be growth in an optimal culture medium and mycelium harvest after determinate time which depends of the fungal species. This time is very important because is necessary to obtain the highest number of fungal cells in metaphase stage (Carbu, 2006; Garrido et al., 2009b). Chromosomes are condensed and highly coiled in metaphase, which makes them most suitable for visual analysis. After young mycelium is harvested, it is necessary to produce protoplasts using different mixes of lysing enzymes, which digest the fungal cell wall after incubation. Protoplast suspensions are mixed with low melting point agarose, adjusted to final concentration of $1 \times 10^{8}$ protoplast $\mathrm{ml}^{-1}$, and solidified plugs of agarose containing protoplast are digested with proteinase $\mathrm{K}$. The digestion produces pores in the plasma membrane, providing the possibility to extract the chromosomal by PFGE (Garrido et al., 2009b).

Gels are prepared with a special type of agarose. It depends of the DNA molecules sizes because there are different commercial preparations, some of them for DNA molecules higher than $10 \mathrm{Mb}$, i.e. PFGE TMMegabase agarose (Bio-Rad). Plugs are cast in the gel, and this is placed in the center of the hexagon formed by the 24 electrodes. Many parameters of the electrophoresis have to be optimized, since the type and concentration of running buffer, temperature of buffer, voltage and time of pulses, angles of electric fields. Depending of instrument setup, we can resolve the electrophoretic karyotype (EK) only with one experiment, like in the case of Botrytis cinerea; or even it could be necessary two different steps/running conditions, due to the high differences in sizes of the chromosomal DNA molecules. After electrophoresis, gels are stained using i.e. ethidium bromide and visualized using a UV light system.

PFGE has been widely used by our group to study the genome organization and Chromosomal Polymorphisms (CPL) in B. cinerea and C. acutatum. We have determined the number and sizes of chromosomes in both species, and therefore we have estimated the 
genome size for these fungi; the high level of CPL displayed by them, represented in the different EK profiles showed by the strains; and PFGE has made possible downstream applications such as Southern-blot analysis using different probes. All the results accumulated during the last years have provided a better understanding about the genome organization and the molecular bases of asexual and sexual reproduction of these fungi. They proved that polymorphism has been observed in both asexual and sexual fungi and most likely results from both mitotic and meiotic processes, especially in the case of Botrytis cinerea (Vallejo et al., 2002).

When a study of PFGE has made, it is usual to find chromosomal bands of different intensity and therefore it is important to consider several technical aspects that can have influence in the interpretation of the final results, and the conclusions obtained: i) a double band could be composed of two coumpounds of a couple of homologous chromosomes or of two heterologous chromosomes of similar size, and ii) two homologous chromosomes can differ in size and appear like two heterologous ones. Due to this fact, depending on the aims of the study, sometimes further hybridization studies are necessary in order to determine the linkage groups of each of the bands (Carbu, 2006; Vallejo et al., 1996).

Botrytis cinerea strains studied by our group were isolated from different hosts and geographical origins. We found different EK profiles between isolates, which did not follow any correlation with the host, year of isolation, or phenotypical characteristics. We have found that the number of chromosomal bands varied between 5 and 12, and they ranged between 1.80 and $3.8 \mathrm{Mb}$. These results made possible to estimate the minimal genome size of B. cinerea genome, found between 14.5 and $22.7 \mathrm{Mbp}$ (Carbu, 2006; Vallejo et al., 1996, 2002) (Fig. 1a).

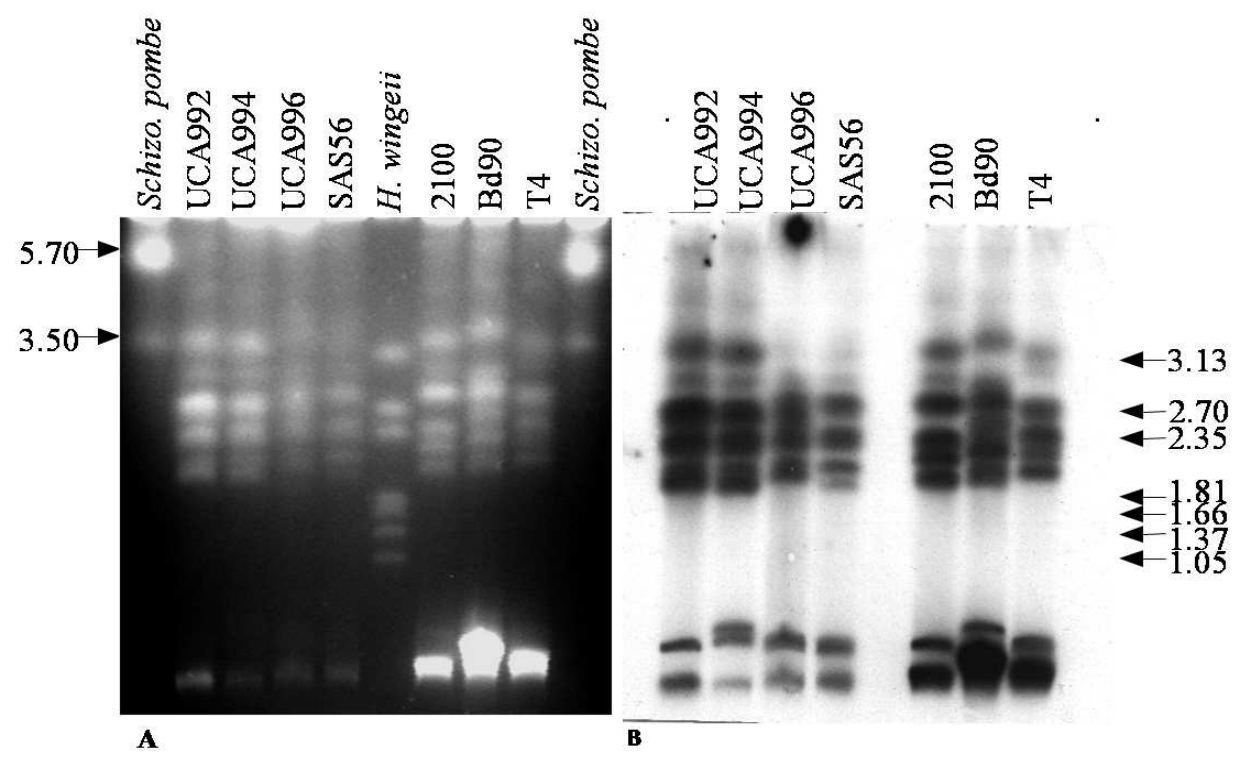

Fig. 1. A.- PFGE chromosomal separation of selected B. cinerea isolates. The molecular sizes were estimated using Schizosaccharomyces pombe (line 1 and 10), and Hansenula wingeii (line 6) chromosomes as reference molecular markers (Bio-Rad). B.- Southern-blot hybridization using a telomeric DNA probe to hybridise the PFGE separated chromosomal bands. 
The B. cinerea strains showed a high level of CLPs, revealing the facility to support chromosomal rearrangements in this species, and could be the basis of the high degree of adaptability to the environmental conditions. Our group has also studied crosses between strains with different EK profiles. This study had as main aim to analyze the chromosomal rearrangements and chromosomal segregation in the crossed strains, in order to clarify the controversy appeared about the possibility that a high level of CLPs between strains, could inhibit meiosis (Zeigler, 1998), and therefore to be one possible reason to explain the low level of sexual reproduction that take place in B. cinerea under natural conditions (Carbu, 2006; Giraud et al., 1997).

The crosses between strains produced fertile strains (more than 100 ascopores studied) and our results demonstrated that chromosomal rearrangements did not affect the capacity to reproduce sexually in $B$. cinerea. It was observed than only several isolates recovered the parental EKs. New chromosomes sizes were identified and some bands were lost from the parental to descendants EKs. All these results, along with a segregation analyses carried out in the decendants, represented strong evidence that some strains might not be haploid, and that aneuploidy and differences in ploidy levels are present in this species (Vallejo et al., 2002). Our group has also studied how during a long period of time, reproducing the fungus "in vitro", there were not detected changes in the EK of a given strain. All results together, proved that mitotic growth does not provide EK variability in this fungus, being the chromosomal rearrangements generated after meiotic recombination the causal agent of EK variability in B. cinerea (Carbu, 2006).

In the case of the species C. acutatum, there were not data published about the EKs and CLPs among isolates until the last 2009 (Garrido et al., 2009b). PFGE had been used with other species of this genus, like C. gloeosporioides (Masel et al., 1993) and C. lindemouthianum (O’Sullivan et al., 1998). Colletotrichum spp. displayed an estimated genome sizes higher than $B$. cinerea. Protocols to separate the chromosomes molecules were carried out in two different experimental setups, including variations in the pulse of electric field, percentage of agarose gels and duration of the assays (Masel et al., 1993), i.e. for separation of larger chromosomal molecules in C. gloeosporioides, Masel et al. (1993) optimized an PFGE approach running a electrophoresis of seven days long. During this experiment, it was necessary to replace the running buffer each two days to obtain a better resolution in the final image. Similar protocols were used to resolve EK from C. lindemouthianum strains(O’Sullivan et al., 1998).

The karyotype of C. acutatum was studied by our group in several strains isolated from different geographical origins. They had showed differences in the morphological characteristics in relation to the color and texture of mycelium, ratio of growth in different medium, pathogenicity and level of conidia production (Garrido et al., 2008, 2009b). Protocol to obtain C. acutatum protoplasts and the PFGE conditions to separate chromosomes were optimized based on our previous experience with $B$. cinerea. We optimized a PFGE running conditions to separate chromosomes between approximatele 0.1 and $9 \mathrm{Mb}$ after only $72 \mathrm{~h}$. of running. This protocol improved substantially those previously described for Colletotrichum spp., which took longer due to the two steps needed to resolve the complete karytopyes. Those longer protocols (Masel et al., 1993) were also tested, and we got the same number and sizes of chromosomal bands, proving the improvement of our optimized 72-hours protocol (Garrido et al., 2009b). 
C. acutatum strains showed EK profiles containing between six and nine chromosomal bands with different sizes ranging from 0.1 and $8 \mathrm{Mb}$. The total minimal genome size estimated for C. acutatum ranged between 29 and $36 \mathrm{Mb}$, which is similar to that previously described for other species of Colletotrichum (Masel et al., 1993; O’Sullivan et al., 1998). We observed CLPs between strains studies but further analyses with a high number of isolates could be necessary in order to obtain strong conclusions about the CLPs showed by the species and how this variability could affect the sexual and asexual reproduction of this species in the environment (Garrido et al., 2009b).

PFGE gels from B. cinerea and C. acutatum were used in downstream applications, like Southern-blot analyses. Gels were transferred to Hybond-N membranes and they hybridised with a telomeric probe confirming that all the bands represented chromosomes. The description of Southern-blot analyses will be described in the next section, but it proved how PFGE, not only provides the possibility to obtain interesting conclusions about the biology and genome organization of these fungi, but also gel electrophoresis techniques are often the starting point for interesting downstream applications that provide more information in the researches of these fungi (Fig. 1b).

In our PFGE studies in B. cinerea and C. acutatum, it has not been observed a higher EKs variability that showed by phenotypic characteristics among strains (Carbu, 2006; Garrido et al., 2008, 2009a, 2009b; Rebordinos et al., 2000; Vallejo et al., 1996). Phenotypic features were very highly variable between strains with the same EKs. Therefore, we cannot conclude that there is a direct relation between morphological, physiological and pathogenic variability directly related with heterokaryosis, aneuploidy and a variable level of ploidy among strains. New proteomics approaches to B. cinerea and Colletotrichum spp., which will be described during next pages, is contributing with very interesting data, that in conjunction with genomic information, disclose that phenotypic variation is more related with the synthesis of proteins and their post-transductional modifications, and not only by genotypes encoding them (Fernández-Acero et al., 2011).

\section{Phylogenetic relationships between strains of Colletotrichum spp. using telomeric fingerprinting}

Colletotrichum acutatum is a widely spread species that can be found throughout the world (Whitelaw-Weckert et al., 2007). C. acutatum causes anthracnose on a number of economically important crops, including woody and herbaceous crops, ornamentals, fruits, conifers and forage plants (Sreenivasaprasad \& Talhinhas, 2005). It was classified as an organism of quarantine significance in Canada from 1991 to 1997, in the UK and the EU since 1993, and it can be found widely spread in the southwest region of USA (EPPO/CABI, 1997; Garrido et al., 2009a; Mertely and Legard, 2004). Investigations of C. acutatum were focused in two main aspects of the pathogen: i) cultural and morphological studies (Afanador-Kafuri et al., 2003; Denoyes-Rothan \& Baudry, 1995; Garrido et al., 2008;) and ii) molecular approaches using molecular techniques including isoenzyme comparisons, Restriction Fragment Length Polymorphism (RFLP) analyses of mitochondrial DNA, Amplified Fragment Length Polymorphism (AFLP), AT rich analyses, Random Amplified Polymorphic DNA (RAPD), and ITS sequences analyses for specific PCR sequencing and identification (Buddie et al., 1999; Freeman et al., 1993; Garrido et al., 2009a, 2009b; Sreenivasaprasad et al., 1996; Talhinhas et al., 2005). 
Sreenivasaprasad \& Talhinhas (2005) studied C. acutatum populations from several hosts and different geographical origins. They established molecular groups based on sequences analyses of the internal transcribed spacers (ITS) of ribosomal DNA polymorphic regions (Sreenivasaprasad \& Talhinhas, 2005). ITS regions have been widely used on molecular approaches for studying relationship between microorganisms, and it is also very useful regions for designing molecular approaches to identification and diagnostic protocols, due to the high variability showed by the sequences among species and even strains (Garrido et al., 2009a). The classification carried out by Sreenivasaprasad \& Talhinhas (2005), established eight molecular groups for $C$. acutatum species. These molecular groups have been widely used to study the genotypic and phenotypic diversity of this fungus, and to classify isolates from different origin (Whitelaw-Weckert et al., 2007).

During the last years, we carried out a study to classify a worldwide collection of $C$. acutatum strains isolated from thirteen countries (Australia, Canada, France, Germany, Japan, The Netherlands, New Zealand, Norway, Portugal, Spain, Switzerland, USA and UK). For this purpose we used two different molecular approaches in order to study the phylogenetic relationship between strains: i) a sequencing analysis of the internal transcribed spacers (ITS) of the $5.8 \mathrm{~S}$ ribosomal DNA polymorphic regions; ii) a telomeric fingerprinting study by Southern-blot hybridization, using a telomeric probe after RFLP digestions of genomic DNA (Garrido et al., 2009b).

In total, eighty-one 5.8S-ITS sequences were studied, several strains were sequenced by our group, and other ones used from databases such as reference sequences for allocating our strains in the previously established molecular groups for C. acutatum. ITS regions, including 5.8S rDNA, were amplified by conventional PCR using universal primers ITS1 and ITS4 (White et al., 1990). After PCR amplification, products were loaded in a conventional 1\% agarose gel for conventional DNA electrophoresis. Products were cut from the gels using a purification kit, DNA was quantified, and subsequently sequenced in both directions (Garrido et al., 2009b).

The phylogenetic study carried out with the sequences allowed us to allocate the strains into C. acutatum molecular groups described by Sreenivasaprasad \& Talhinhas (2005), but the analysis of bootstrap in the neighbout-joining phylogenetic tree, published by Garrido et al. (2009), showed interesting data about the molecular groups. In base of that analyses, the nine molecular groups previously described (Whitelaw-Weckert et al., 2007), could be grouped in only four groups. Our results proved that A1, A2, A5 A8 and A9 subgroups showed a bootstrap support of $90 \%$, and therefore could be considered such as large group in base to the analyses of the sequences of ITS regions (Garrido et al., 2009b). The same result was observed for subgroups A6 and A4, since these subgroups clustered together with a strong bootstrap support of $91 \%$ (Garrido et al. 2009). Our results supported a new classification into four molecular groups instead the nine previously described for this species in base to the ITS sequences (Garrido et al., 2009b).

The phylogenetic analyses showed that the majority of the strains studied grouped in the group A2. This happened because many strains from Spain were included in the analyses. The results proved the high level of similarity between $C$. acutatum strains isolated from Spain. It is also interesting that the A2 group included, principally, isolates from Spain, Portugal, France, UK and USA. C. acutatum was first described in the southwest region of 
the USA, and then it was observed in France and UK at the beginning of the 80s. It is not clear how the pathogen was introduced into production fields in Europe, but it is thought that the pathogen could have arrived since the American nurseries to the EU (Freeman \& Katan, 1997). It should have arrived to France, UK and the Iberian Peninsula fields. The arrival of the pathogen was facilitated by the intense international trade between these countries related with strawberry crop. Therefore the fungus could be introduced by infected plants, contaminated soil associated with strawberry crowns at planting, and quiescent infections on strawberry leaves or fruits (Garrido et al., 2008, 2009b; Leandro et al., 2001, 2003).

In order to complete the phylogenetic classification of our C. acutatum strain collection, a different molecular approach was carried out. The results obtained were compared with those from the ITS sequences analyses. We used the profiles obtained after restriction enzymes digestions of genomic DNA, and then hybridized with a telomeric probe by Southern-blot hybrisization. Genomic DNA of C. acutatum strains were digested to completion with several restriction enzymes in independent experiments (BamHI, EcoRI, HindIII and PstI). Gel electrophoresis is an intermediate point of the complete protocol. It make possible to separate the DNA fragments obtained after the restriction enzymes digestions. In this case, we used a 1.5\% agarose gel, and electrophoresis was carried out in a conventional horizontal tray for DNA electrophoresis (Bio-Rad). After separation of digested fragments, gels were blotting to Hybond-N membrans, being ready for subsequently hybridization (Garrido et al., 2009b).

For Southern-blot hybridization we used a telomeric probe to get hybridization in the telomeric regions. These regions are located at the end of the lineal chromosomes of most eukaryotic organisms, and they are named telomeres. Telomeres are regions of repetitive DNA sequences that protect the end of the chromosome from deterioration or from fusion with neighboring chromosomes. The repeated sequences is dependent of the species. For $C$. acutatum telomeres, we produced our telomeric probe, (TTAGGG)n, by PCR in the absence of a template using (TTAGGG) 5 and (CCCTAA) 5 primers as it was described by ljdo et al. (Ijdo et al., 1991). The Hybond-N membranes were allowed to hybridize with the telomeric probe; films images were digitalized and telomeric profiles were analysed using Fingerprinting II software v3.0 (Bio-Rad).

The experimental setup described provided the possibility to obtain two different kinds of results/conclusions from the study: I) Selected restriction enzymes used for RFLP did not produce any cut in the telomeric regions of $C$. acutatum strains. Each band represents a physically distinct telomere extremity. Therefore, taking into consideration the higher number of telomeric extremities and then divided into two, we can determine the number of chromosomes among strains studied. II) The fingerprinting analyses of the telomeric profiles, carried out using Fingerprinting II software, make possible to produce phylogenetic trees based in the similarity of the profiles showed among the strains. Therefore, these results could be compared with those obtained from phylogenetic groups based on ITS sequences.

Among the fifty-two isolates analysed by telomeric fingerprinting, the number of band or telomeres oscillated between twelve and eighteen. Therefore, the minimum number of estimated chromosomes was from six to nine among C. acutatum isolates (Garrido et al., 
2009b). In this study the number of strains studied was higher than those studied by FPGE, and although fingerprinting analyses did not make possible to study the chromosomal length polymorphisms among the isolates, the minimum numbers of estimated chromosomes are coincident with those obtained from FPGE analyses, showed in the last section of this chapter.

The telomeric profiles obtained for each isolate of $C$. acutatum were analysed. UPGMA dendogram showed a representative grouping among the isolates, which was coincident with the grouping in the neighbuor-joining phylogenetic tree based on sequences of rDNA ITS regions (Garrido et al., 2009b). All the strains previously classified in the A2 molecular groups, also clustered in a large group with more than $70 \%$ of similarity based in this case in the telomeric fingerprinting profiles. These results proved the high level of similarity shows by these isolated, not only based in sequence similarity of one specific region but also in their genotypes and genome organization among $C$. acutatum strains, which suggests a common origin of the strains among the different molecular groups (Garrido et al., 2009b; Talhinhas et al., 2005).
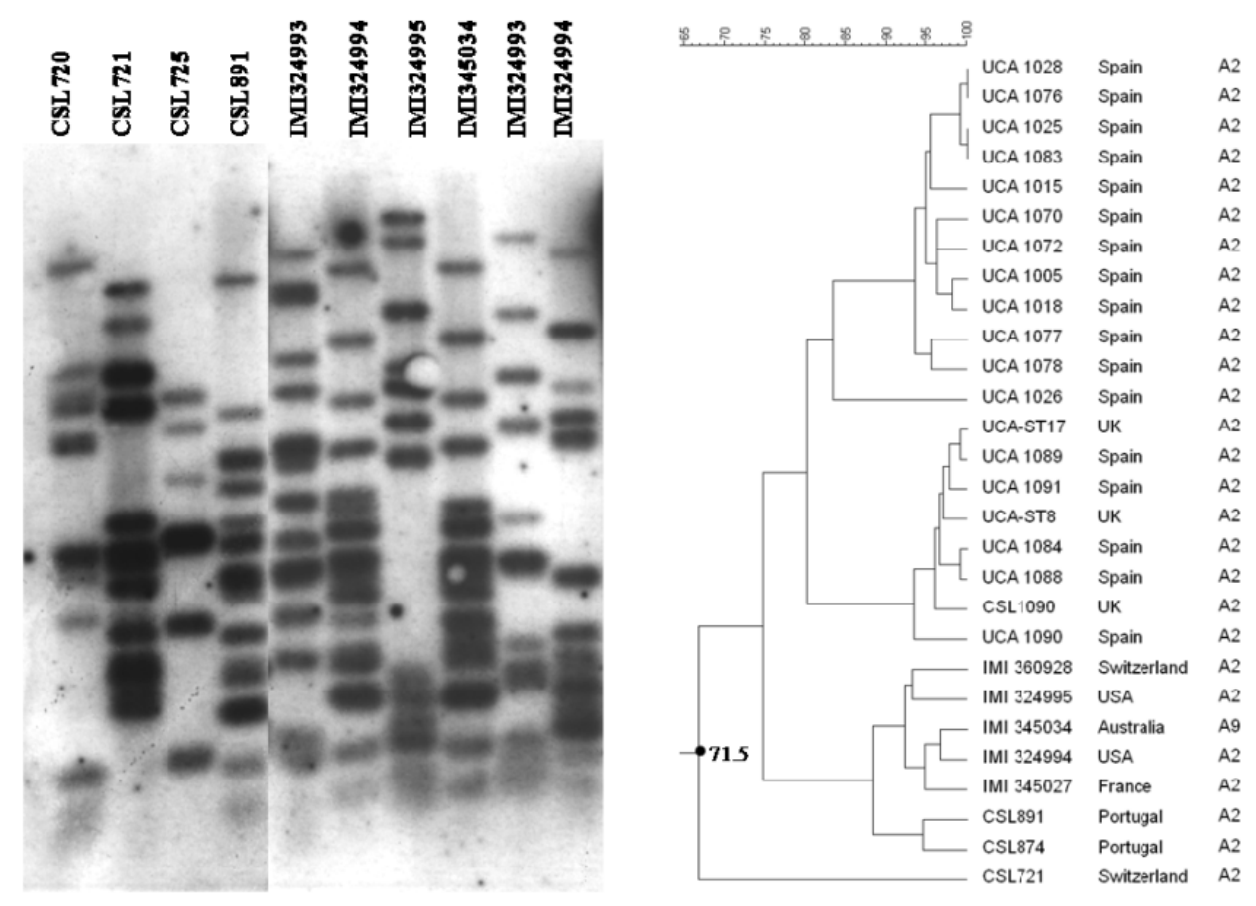

Fig. 2. Left.- Telomeric fingerprinting patterns obtained by telomeric hybridisation of Southern blots from HindIII-DNA digestions. Right.- Combined UPGMA dendograms with the $C$. acutatum isolates belonging to $\mathrm{A} 2$ group, based on Dice coefficients generated using a composite data set from individual experiments of each enzyme digestion (BamHI, EcoRI, HindIII and PstI) hybridised with a telomeric probe. 


\section{Develop of molecular methods for detection and identification of phytophatogenic fungi - Monitoring of the diseases causing by Colletotrichum spp.}

Many fungal plant pathogens produce similar symptoms when they develop diseases among different hosts. Currently, the ability to detect, identify and quantify plant pathogens accurately is the cornerstone of plant pathology (Garrido et al., 2011). The reliable identification of the organism(s) responsible for a crop disease is an essential prerequisite to apply the correct disease management strategies and the most appropriate control measures to take. Besides, many pathogens are subjected to special regulation through quarantine programs agreed among producer countries. For all these reasons, pathogen identification is crucial to all aspect of fungal diagnostics and epidemiology in the field of plant pathology, but also in medical science, environmental studies and biological control (Alastair McCartney et al., 2003; Atkins et al., 2003).

Since the 1990's, new methods based on molecular biology have provided new tools for more accurate and reliable detection, identification and quantification of plant pathogens. These methods are based on immunological and DNA/RNA study strategies, including, amongst others: RFLP analyses of mitochondrial DNA (Garrido et al., 2008; Sreenivasaprasad et al., 1992), AFLP, AT-rich analyses (Freeman et al., 2000a, 2000b), RAPDDNA (Whitelaw-Weckert et al., 2007), genus-specific and species-specific PCR primers (Garrido et al., 2008; Martínez-Culebras et al., 2003; Mills et al., 1992; Sreenivasaprasad et al., 1996), real-time PCR studies (Garrido et al., 2009a), and ELISA assays (Hughes et al., 1997). Diagnosis time can be reduced from a period of weeks, typically experienced with culture plating, to only a few days, thus allowing the appropriate control methods to implemented much sooner and more effectively (Atkins et al., 2003).

Advances in polymerase chain reaction technology have opened alternative approaches to the detection and identification of fungal pathogens. The development of PCR technology relies on three fundamental steps: i) the selection of a specific target region of DNA/RNA to identify the fungus; ii) extraction of total community DNA/RNA from the environmental sample; iii) a method for identifying the presence of the target DNA/RNA region in the sample (Garrido et al., 2011). Our group have optimised a very high sensitive protocol for diagnosis and identification of the fungal genus Colletotrichum, and the species C. acutatum and C. gloeosporioides (Garrido et al., 2009a).

The sensitivity of PCR-based protocols depends mainly on the instrumentation and technique used (i.e. conventional PCR vs. real-time PCR), but in a high proportion of cases this sensitivity depends on the quality of the total community DNA/RNA extracted from the environmental samples. Garrido et al. (2009) optimized a DNA extraction protocol that can be used for samples of strawberry plant material directly, or from fungal colonies removed from an agar plate. This method uses sample material physically ground using a grinding machine, in the presence of CTAB lysis buffer. The lysated samples are washed in various chemical products (chloroform, isopropanol, ethanol, etc.) and then the final step involves using Magnesil ${ }^{\circledR}$ beads and GITC lysis buffer (guanidinium thiocyanate buffer) in a Kingfisher robotic processor (Kingfisher ML, Thermo Scientific). The new method was tested with roots, crowns, petioles, leaves and fruits and the extraction methods always showed very high yields of DNA in both quantity and quality. Although, a wide range of 
commercial kits are available for extraction of fungal DNA, they can represent a high cost per sample analysed, and they are not always totally reliable in not co-extracting PCR inhibitors, needed a dilution of samples prior to PCR reactions. The optimised protocol did not co-extracted PCR-inhibitors from any samples, and therefore, the sensitivity of the detection protocol is improved using this DNA extraction protocols (Garrido et al., 2011).

To date, conventional PCR has been a fundamental part of fungal molecular diagnosis, but it shows several limitations: i.e. gel-based methods, possibility of quantification, sensitivity, etc. The development of real-time PCR has been a valuable response to these limitations (Garrido et al., 2011). This technology improve the sensitivity, accuracy and it is less timeconsuming that conventional end-point PCR. For development and optimization of Colletotrichum diagnosis protocols, the commonly-used ribosomal RNA genes were used, because of the highly variable sequences of the internal transcribed spacers ITS1 and ITS2, which separate the 18S/5,8S and 5,8S/28S ribosomal RNA genes, respectively (Garrido et al., 2009a). Specific genus and species sets of primers and probes were designed for real-time PCR amplifications using TaqMan ${ }^{\circledR}$ chemistry technology. This system consists of a fluorogenic probe specific to the DNA target, which anneals to the target between the PCR primers; TaqMan ${ }^{\circledR}$ tends to be the most sensitive and simply methods for real-time PCR detection (Garrido et al., 2009a, 2011).

The specificity of all assays was tested using DNA from isolates of six species of Colletotrichum and from DNA of another nine fungal species commonly found associated with strawberry material. All the new assays were highly specific for Colletotrichum spp., C. acutatum and C. gloeosporioides, no cross-reactions were observed with either related plant pathogens or healthy strawberry plant material. The sensitivity of the new real-time PCR assays was compared with that of previously published conventional PCR assays; they were confirmed to be 100 times more sensitive than the latter. The C. acutatum-specific real-time PCR assay was also compared with an existing ELISA assay for the diagnosis of this pathogen. Real-time PCR permitted the detection of the pathogen in samples that gave negative results for $C$. acutatum using ELISA. The real-time PCR assay detected the equivalent of 7.2 conidia per plant inoculated with a serial dilution of C. acutatum spores, demonstrating the high degree of sensitivity of the method (Garrido et al., 2009a).

The new protocols were tested for monitoring the development of anthracnose disease in strawberry in the field in the south of Spain. The real-time PCR results showed a progressive increase of target DNA between January and June. The results showed that an increase in lesion development was accompanied by an increase in the amount and incidence of the pathogen as the season progressed. These results showed that new methods are suitable for diagnosis, identification and monitoring of the disease using field samples of strawberry and also, they permitted the detection of the pathogens from artificially infected symptomless plant material. Therefore, the methods described, based on real-time PCR, proved useful for studying the epidemiological routes of these strawberry pathogens in fields and nurseries (Garrido et al., 2009a, 2011).

\section{Proteomics approaches of phytopathogenic fungi}

In spite of the advances done by the described techniques above, nowadays proteomics is the most realistic and effective set of tools to unravel complex mixtures of proteins, 
describing the current molecular biology age as "post-genomic era". The term proteome was coined in 1995 by Wilkins et al (Wilkins et al., 1995), later the term proteomics appeared by James et al. (James, 1997). Proteome is defined as the complete set of proteins expressed by an organism, in a particular biological state. Proteomics may be introduced as a set of techniques that allow to study and to describe the proteome. The impact of the proteomic approaches is mainly based in a group of widely used techniques such as liquid chromatography or two dimensional gel electrophoresis, to separate complex protein mixtures, defining the proteome. However, the increasing relevance of these studies has been pushed by the improvements done in mass spectrometry system, allowing the analysis of peptides and proteins and/or by the increase number of proteins entries in the databases, making easier protein analysis and identification.

Main proteome characteristic is that it is a high dynamic system. It is even more complex than genomics, due to while the genome of an organism is more or less constant, the number of obtained proteomes from a specific genome is almost infinite. It depends of the assayed cell, tissue, culture conditions, etc. Each change produces a modification in the observed proteome. An additional factor of complexity is that there are changes that occur in proteome that are not encoded in the genome. These changes are mainly based on two sources, (i) the editing of the mRNA and (ii) post-translational modifications (PTMs) that normally serve to modify or modulate the activity, function or location of a protein in different contexts physiological or metabolic. There are more than 200 different described PTMs (phosphorylation, methylation, acetylation, etc.). They transform each single gene into tens or hundreds of different biological functions. Before proteomics achievements, the differential analysis of the genes, that were expressed in different cell types and tissues in different physiological contexts, was done mainly through analysis of mRNA. However, for wine yeast it has been proved that there is no direct correlation between mRNA transcripts and protein content (Rossignol et al., 2006). It is known that mRNA is not always translated into protein, and the amount of protein produced by a given amount of mRNA depends on the physiological state of the cell. Proteomics confirms the presence of the protein and provides a direct measure of its abundance and diversity.

In terms of methodology, proteomics approaches are classified in two groups, (i) gel free systems, based in the use of different chromatography methods, and (ii) gel based methods, using mainly two dimensional polyacrylamide gel electrophoresis (2DE), that will be the core of our discussion. As a schematic summary, the typical workflow of a proteomic experiment begins with the experimental design. It must be deeply studied, and it will delimit the obtained conclusions, even more when comparison between two strains, cultures or physiological stages between others, are done. From an optimal point of view, only one factor must change between the different assayed conditions (Fernández-Acero et al., 2007a, $2007 \mathrm{~b}$ ). It must contain the use of different biological replicates depending of the used strategy, usually from 3 to 5 . The next key step is to obtain a protein extract with enough quality to separate the complex mixture of proteins. Usually, the protein extraction is done in sequential steps (Garrido et al., 2010). First, the biological sample is disrupted using mechanical or chemical techniques. Then, proteins are precipitated and cleaned. Most of the protocol use acetone and trichloroacetic acid. During the next step the proteome is defined and visualized using electrophoretic techniques. 2DE has been widely used for this purpose. Using this technique proteins are separated using two different parameters. During the first dimension, proteins are separated by their isoelectric point using an isoelectrofocusing (IEF) 
device. Then, the focused strips are used to load in a polyacrylamide gel, where the proteins are separated by their molecular weight. This system allows the separation of hundreds of proteins from a complex mixture. The gels are visualized with unspecific protein stains (those that stain total proteins, such as Coomassie, Sypro, Silver, etc.), or specific ones (those staining solution prepared to detect specific groups of proteins, mainly post-translationals modifications, i.e. Phospho ProQ diamond). The gels are digitalized and analyzed with specific software to reveal the significant spots. Those spots are identified using mass spectrometry. MALDI TOF/TOF is commonly used for 2DE approaches. The huge list of identified proteins obtained is studied to reveal the biological relevance of each identification.

Unfortunately, the number of papers related to fungal proteomics is still poor compared with the application of this technology to other biological sources. As an example, a simple search in WOK website (web of knowledge, http://www.accesowok.fecyt.es/) get 809 entries when the terms "proteom*"and "fung*" are used, whereas 51237 entries are displayed when "proteom ${ }^{* \prime}$ is used alone. In spite of the numerical results obtained may vary depending of the used keywords and web resource, the fact is that there is a lot of work to do to bring fungal proteomic information at the same level that is obtained with other biological sources. This lack is mainly caused by (i) the difficulties to obtain proteins with enough quality to 2DE separations and (ii) the lack of protein sequences listed in the databases. Our research group was pioneer solving these problems and preparing the first proteomic approaches to the phytopathogenic fungi Botrytis cinerea (Fernández-Acero et al. 2006).

Fungi posse strong cell walls. This makes difficult the cell breakage using standard protocols. Moreover, fungal proteins extract are characterised by its high concentration of glycosylated proteins that produces dense extracts, dragging a lot of impurities that disturb protein electrofocusing. We optimized a protocol based on a first phosphate buffer solubilisation followed by a typical TCA/Acetone precipitation. Using this protocol we developed the first proteomic map of Botrytis cinerea (Fernández-Acero et al., 2006b). Using this optimized approach we prepared a differential proteomics approach based on 2DE, comparing the proteomes of two B. cinerea strains differing in virulence (Fernández-Acero et al., 2007b). In spite of this protocol has been widely cited and used (Cobos et al., 2010; Fernández-Acero et al., 2010, 2011; Michielse et al., 2011; Moreira et al., 2011; Sharma et al., 2010; Yang et al., 2011), our recent data suggest that the phosphate buffer solubilisation produces an artificial enrichment of soluble proteins in our assayed extracts. For this reason, we improved our method using a phenol based protocol preparing a Botrytis cinerea map during cellulose degradation (Fernández-Acero et al., 2010). Based on this protocol, adding a previous step of precipitation with DOC, we developed the analysis of the main fungal subproteome, the secretome. We identified 76 secreted proteins from cultures where the virulence was induced with different plant-based elicitors (Fernández-Acero et al., 2010). New projects to unravel proteome content of Botrytis cinerea and Colletotrichum acutatum are running.

All the proteomic approaches developed on B. cinerea has been facilitated by the availability of fungal genome sequence (Amselem et al., 2011) (http://urgi.versailles.inra.fr/ Species/Botrytis, and http://www.broadinstitute.org/annotation/genome/botrytis_ cinerea/Home.html). Summarizing all our identified spots, we do not get the $3 \%$ of the 
predicted genome. The method to capture new fungal proteins, its identification by mass spectrometry and to determine their biological relevance needs to be determined yet. By using our previous experience with $B$. cinerea, we are developing proteomic approaches to C. acutatum. Its conidial germination, mycelia dataset and secretome are characterized by 2DE. The key challenge is in our opinion, the use of the collected information to develop new methodologies to fight against plants pathogens. As a future prospect, the development of new environmental friendly proteomics-based fungicides has been discussed (FernándezAcero et al., 2011).

\section{Acknowledgements}

This research has been financed by the Spanish Government DGICYT - AGL2009-13359CO2/AGR, by the Andalusian Government: Junta de Andalucía, PO7-FQM-002689, http://www.juntadeandalucia.es/innovacioncienciayempresa; Programa Operativo 20072013 (FEDER-FSE) (18INSV2407, 18INSV2610), and by the CeiA3 International Campus of excellence in Agrifood (18INACO177.002AA, http://www.uco.es/cei-A3/). Victoria E. González-Rodríguez was financed by the grant FPU of the Ministerio de Educación, Government of Spain, Ref. AP2009-1309; Eva Liñeiro was financed by the grant of the University of Cádiz Ref. 2010-152.

\section{References}

Afanador-Kafuri, L., Minz, D., Maymon, M., Freeman, S. (2003). Characterization of Colletotrichum isolates from Tamarillo, Passiflora, and Mango in Colombia and identification of a unique species from the genus. Phytopathology, Vol. 93, pp. 579587, 0031-949X

Agrios, G.N. (2005). Plant Pathology. (5th Ed). Elsevier Academic Press, ISBN: 13: 9780120445653, San Diego, CA

Alastair McCartney, H., Foster, S.J., Fraaije, B.A., Ward, E. (2003). Molecular diagnostics for fungal plant pathogens. Pest Management Science, Vol. 59, pp. 129-142, 1526-498X

Amselem, J., Cuomo, C.A., van Kan, J.A.L., Viaud, M., Benito, E.P., Couloux, A., Coutinho, P.M., de Vries, R.P., Dyer, P.S., Fillinger, S., Fournier, E., Gout, L., Hahn, M., Kohn, L., Lapalu, N., Plummer, K.M., Pradier, J.-., Quévillon, E., Sharon, A., Simon, A., Have, A., Tudzynski, B., Tudzynski, P., Wincker, P., Andrew, M., Anthouard, V., Beever, R.E., Beffa, R., Benoit, I., Bouzid, O., Brault, B., Chen, Z., Choquer, M., Collémare, J., Cotton, P., Danchin, E.G., Da Silva, C., Gautier, A., Giraud, C., Giraud, T., Gonzalez, C., Grossetete, S., Güldener, U., Henrissat, B., Howlett, B.J., Kodira, C., Kretschmer, M., Lappartient, A., Leroch, M., Levis, C., Mauceli, E., Neuvéglise, C., Oeser, B., Pearson, M., Poulain, J., Poussereau, N., Quesneville, H., Rascle, C., Schumacher, J., Ségurens, B., Sexton, A., Silva, E., Sirven, C., Soanes, D.M., Talbot, N.J., Templeton, M., Yandava, C., Yarden, O., Zeng, Q., Rollins, J.A., Lebrun, M.-., Dickman, M. (2011). Genomic analysis of the necrotrophic fungal pathogens Sclerotinia sclerotiorum and Botrytis cinerea. PLoS Genetics, Vol. 7, No. 8, e1002230. doi:10.1371/journal.pgen.1002230, 1553-7390

Atkins, S.D., Clark, I.M., Sosnowska, D., Hirsch, P.R., Kerry, B.R. (2003). Detection and quantification of Plectosphaerella cucumerina, a potential biological control agent of 
potato cyst nematodes, by using conventional PCR, Real-Time PCR, Selective Media, and Baiting. Applied and Environmental Microbiology, Vol. 69, pp. 4788-4793, 0099-2240

Bailey, J.A., Jeger, M.J. (1992). Colletotrichum: biology, pathology and control. CAB international, ISBN: 0-85198-756-7, Wallingford

Buddie, A.G., Martínez-Culebras, P.V., Bridge, P., García-López, M.D., Querol, A., Cannon, P.F., Monte, E. (1999). Molecular characterization of Colletotrichum strains derived from strawberry. Mycological Research, Vol. 103, pp. 385-394, 0953-7562

Carbu, M. (2006). Estudio de la variabilidad genetica y organizacion cromosomica en el hongo fitopatogeno "Botrytis cinerea". Thesis doctoral. University of Cádiz, Cádiz

Cobos, R., Barreiro, C., Mateos, R.M., Coque, J.R. (2010). Cytoplasmic- and extracellularproteome analysis of Diplodia seriata: A phytopathogenic fungus involved in grapevine decline. Proteome Sciences, Vol. 8, doi: 10.1186/1477-5956-8-46, 1477-5956

Coley-Smith, J.R., Verhoheff, K., Jarvis, W.R. (1980). The Biology of Botrytis. Academic Press, ISBN 0-1217 98508X, London, UK

Denoyes-Rothan, B., Guerin, G., Lerceteau-Kohler, E., Risser, G. (2004). Inheritance of resistance to Colletotrichum acutatum in Fragaria $x$ ananassa. Phytopathology, Vol. 95, pp. 405-412, 0031-949X

Denoyes-Rothan, B., Baudry, A. (1995). Species identification and pathogenicity study of French Colletotrichum strains isolated from strawberry using mophological and cultural characteristics. Phytopathology, Vol. 85, pp. 53-57, 0031-949X

Elad, Y., Williamson, B., Tudzynski, P., Delen, N. (2004). Botrytis: Biology, Pathology and Control. Springer, ISBN: 978-1-4020-6586-1, Dordrecht, The Netherland.

EPPO/CABI (1997). Quarantine Pests for Europe (2nd edition). Edited by Smith IM, McNamara DG, Scott PR, Holderness M. CABI International, Wallingford, UK, 1425 pp.

Faretra, F., Antonacci, E., Pollastro, S. (1988). Sexual bahaviour and matting system of Botryotinia fuckeliana (Botrytis cinerea). Microbiology, Vol. 134, No. 9, pp. 2543-2550, 1350-0872

Faretra, F., Antonacci, E. (1987). Production of apothecia of Botryotinia fuckeliana (de Bary) Whetz under controled environmental conditions. Phytopathologia Mediterranea, Vol. 26, pp. 29-35, 0031-9465

Fernández-Acero, F.J., Colby, T., Harzen, A., Carbú, M., Wieneke, U., Cantoral, J.M., Schmidt, J. (2010). 2-DE proteomic approach to the Botrytis cinerea secretome induced with different carbon sources and plant-based elicitors. Proteomics, Vol. 10, pp. 2270-2280, 1615-9853

Fernández-Acero, F.J., Carbú, M., Garrido, C., Vallejo, I., Cantoral, J.M. (2007a). Proteomic Advances in Phytopathogenic Fungi. Current Proteomics, Vol. 4, pp. 79-88, 1570-1646

Fernández-Acero, F.J., Jorge, I., Calvo, E., Vallejo, I., Carbú, M., Camafeita, L.E., Garrido, C., López, J.A., Cantoral, J.M., Jorrin, J. (2007b). Proteomic analysis of phytopathogenic fungus Botrytis cinerea as a potential tool for identifying pathogenicity factors, therapeutic targets and for basic research. Archives of Microbiology, Vol. 187, pp. 207$215,1432-072 X$

Fernández-Acero, F.J., Carbú, M., Garrido, C., Collado, I.G., Cantoral, J.M., Vallejo, I. (2006a). Screening Study of Potential Lead Compounds for Natural Product-based Fungicides Against Phytophthora Species. Journal of Phytopathology, Vol. 154, pp. 616621, 0931-1785

Fernández-Acero, F.J., Jorge, I., Calvo, E., Vallejo, I., Carbú, M., Camafeita, E., Lopez, J.A., Cantoral, J.M., Jorrin, J. (2006b). Two-dimensional electrophoresis protein profile of 
the phytopathogenic fungus Botrytis cinerea. Proteomics, Vol. 6, No. 1, pp. 88-96, 1615-9853

Fernández-Acero, F.J., Carbú, M., El-Akhal, M.R., Garrido, C., González-Rodríguez, V.E., Cantoral, J.M. (2011). Development of proteomics-based fungicides: New strategies for environmentally friendly control of fungal plant diseases. International Journal of Molecular Sciences, Vol. 12, pp. 795-816, 1422-0067

Freeman, S., Katan, T. (1997). Identification of Colletotrichum species responsible for anthracnose and root necrosis of strawberry in Israel. Phytopathology, Vol. 87, pp. 516-521, 0031-949X

Freeman, S., Minz, D., Jurkevitch, E., Maymon, M., Shabi, E. (2000a). Molecular analyses of Colletotrichum species from Almond and other fruit. Phytopathology, Vol. 90, pp. 608-614, 0031-949X

Freeman, S., Shabi, E., Katan, T. (2000b). Characterization of Colletotrichum acutatum causing anthracnose of Anemone (Anemone coronaria L.). Phytopathology, Vol. 66, No. 12, pp. 5267-5272, 0031-949X

Freeman, S., Pham, M., Rodríguez, R.J. (1993). Molecular genotyping of Colletotrichum species based on arbitrarily primed PCR, A+T-rich DNA, and nuclear DNA analyses. Experimental Mycology, Vol. 17, pp. 309-322, 0147-5975

Garrido, C., Carbú, M., Fernández-Acero, F.J., González-Rodríguez, V.E., Cantoral, J.M. (2011). New Insight in the Study of Strawberry Fungal Pathogens. Genes, Genomes and Genomics, Vol. 5, No. 1, pp. 24-39, 1749-0383

Garrido, C., Cantoral, J.M., Carbú, M., González-Rodríguez, V.E., Fernández-Acero, F.J. (2010). New proteomic approaches to plant pathogenic fungi. Current Proteomics, Vol. 7, pp. 306-315, 1570-1646

Garrido, C., Carbú, M., Fernández-Acero, F.J., Boonham, N., Colyer, A., Cantoral, J.M., Budge, G. (2009a). Development of protocols for detection of Colletotrichum acutatum and monitoring of strawberry anthracnose using real-time PCR. Plant Pathology, Vol. 58, pp. 43-51, 1365-3059

Garrido, C., Carbú, M., Fernández-Acero, F.J., Vallejo, I., Cantoral, J.M. (2009b). Phylogenetic relationships and genome organization of Colletotrichum acutatum causing anthracnose in strawberry. European Journal of Plant Pathology, Vol. 125, pp. 397-411, 0929-1873

Garrido, C., Carbú, M., Fernández-Acero, F.J., Budge, G., Vallejo, I., Colyer, A., Cantoral, J.M. (2008). Isolation and pathogenicity of Colletotrichum spp. causing anthracnose of strawberry in south west Spain. European Journal of Plant Pathology, Vol. 120, pp. 409-415, 0929-1873

Giraud, T., Fortini, D., Levis, C., Leroux, P., Brygoo, Y. (1997). RFLP markers show genetic recombination in Botryotinia fuckeliana (Botrytis cinerea) and transposable elements reveal two sympatric species. Molecular Biology and Evolution, Vol. 14, pp. 1177-1185, 1537-1719

Hughes, K.J.D., Lane, C.R., Cook, R.T.A. (1997). Development of a rapid method for the detection and identification of Colletotrichum acutatum, In: Diagnosis and Identification of Plant Pathogens, Dehne HW, Adam G, Diekmann M, Frahm J, Mauler-Machnik A \& van Halteren P), pp. 113-116. Kluwer Academic, ISBN: 0792347714, Dordrecht (NL).

Ijdo, J.W., Wells, R.A., Baldini, A., Reeders, S.T. (1991). Improved telomere detection using a telomere repeat probe (TTAGGG)n generated by PCR. Nucleic Acids Research, Vol. 19, pp. 4780, 0305-1048 
James, P. (1997). Protein identification in the post-genome era: the rapid rise of proteomics. Quarterly Reviews of Biophysics, Vol. 30, pp. 279-331, 0033-5835

Kim, Y., Nandakumar, M.P., Marten, M.R. (2007). Proteomics of filamentous fungi. Trends in Biotechnology, Vol. 25, pp. 395-400, 0167-7799

Leandro, L.F.S., Gleason, M.L., Nutter, F.W., Wegulo, S.N., Dixon, P.M. (2003). Strawberry plant extracts stimulate secondary conidiation by Colletotrichum acutatum on symptomless leaves. Phytopathology, Vol. 93, pp. 1285-1291, 0031-949X

Leandro, L.F.S., Gleason, M.L., Nutter, F.W., Wegulo, S.N., Dixon, P.M. (2001). Germination and Sporulation of Colletotrichum acutatum on symptomless strawberry leaves. Phytopathology, Vol. 91, pp. 659-664, 0031-949X

Martínez-Culebras, P.V., Querol, A., Suarez-Fernández, M.B., García-López, M.D., Barrio, E. (2003). Phylogenetic relationships among Colletotrichum pathogens of strawberry and design of PCR primers for their identification. Journal of Phytopathology, Vol. 151, pp. 135-143, 0931-1785

Masel, A., Irwin, J.A.G., Manners, J.M. (1993). DNA addition or deletion is associated with a major karyotype polymorphism in the fungal phytopathogen Colletotrichum gloeosporioides. Molecular Genetics and Genomics, Vol. 237, pp. 73-80, 1617-4615

Mertely, J.C., Legard, D.E. (2004). Detection, isolation, and pathogenicity of Colletotrichum spp. from strawberry petioles. Plant Disease, Vol. 88, pp. 407-412, 0191-2917

Michielse, C.B., Becker, M., Heller, J., Moraga, J., Collado, I.G., Tudzynski, P. (2011). The Botrytis cinerea Reg1 protein, a putative transcriptional regulator, is required for pathogenicity, conidiogenesis and for the production of secondary metabolites. Molecular Plant-Microbe Interaction, Vol 24, No. 9, pp. 1074-1085, 0894-0282

Mills, P.R., Sreenivasaprasad, S., Brown, A.E. (1992). Detection and differentiation of Colletotrichum gloeosporioides isolates using PCR. FEMS Microbiology Letters, Vol. 98, pp. 137-144, 0378-1097

Moreira, J., Almeida, R., Tavares, L., Santos, M., Viccini, L., Vasconcelos, I., Oliveira, J., Raposo, N., Dias, S., Franco, O. (2011). Identification of Botryticidal Proteins with Similarity to NBS-LRR Proteins in Rosemary Pepper (Lippia sidoides Cham.) Flowers. The Protein Journal, Vol. 30, pp. 32-38, 1572-3887

O’Sullivan, D., Tosi, P., Creusot, F., Cooke, M., Phan, T., Dron, M., Langin, T. (1998). Variation in genome organization of the plant pathogenic fungus Colletotrichum lindemuthianum. Current Genetic, Vol. 33, pp. 291-298, 0172-8083

Perfect, S.E., Bleddyn Hughes, H., O'Connell, R.J., Green, J.R. (1999). REVIEW: Colletotrichum: A model genus for studies on pathology and fungal-plant interactions. Fungal Genetics and Biology, Vol. 27, pp. 186-198, 1087-1845

Rebordinos, L., Vallejo, I., Santos, M., Collado, I.G., Carbú, M., Cantoral, J.M. (2000). Análisis genético y relación con patogenicidad en Botrytis cinerea. Revista Iberoamericana de Micología, Vol. 17, pp. 37-42, 1130-1406

Rebordinos, L., Santos, M., Vallejo, I., Collado, I.G., Cantoral, J.M. (1997). Molecular characterization of the phytopathogenic fungus Botrytis cinerea. Recent Research Developments in Phytochemistry, Vol. 1, pp. 293-307, 81-308-0052-7

Rossignol, M., Peltier, J., Mock, H., Matros, A., Maldonado, A.M., Jorrín, J.V. (2006). Plant proteome analysis: A 2004-2006 update. Proteomics, Vol. 6, pp. 5529-5548, 1615-9853 
Sharma, N., Rahman, M.H., Kav, N.N.V. (2010). A possible proteome-level explanation for differences in virulence of two isolates of a fungal pathogen Alternaria brassicae. Journal of Plant Biochemistry and Biotechnology, Vol. 19, pp. 40-49, 0971-7811

Sreenivasaprasad, S., Talhinhas, P. (2005). Genotypic and phenotypic diversity in Colletotrichum acutatum, a cosmopolitan pathogen causing anthracnose on a wide range of hosts. Molecular Plant Pathology, Vol. 6, pp. 361-378, 0885-5765

Sreenivasaprasad, S., Sharada, K., Brown, A.E., Mills, P.R. (1996). PCR-based detection of Colletotrichum acutatum on strawberry. Plant Pathology, Vol. 45, pp. 650-655, 1365-3059

Sreenivasaprasad, S., Brown, A.E., Mills, P.R. (1992). DNA sequence variation and interrelationships among Colletotrichum species causing strawberry anthracnose. Physiological and Molecular Plant Pathology, Vol. 41, pp. 265-281, 0885-5765

Sutton, B.C. (1992). The genus Glomerella and its anamorph Colletotrichum, In: Colletotrichum: Biology, Pathology and Control, Bailey, J.A. \& Jeger, M.J., pp. 1-26, CBA International, ISBN: 0-85198-756-7, Wallingford, UK.

Talhinhas, P., Sreenivasaprasad, S., Neves-Martins, J., Oliveira, H. (2005). Molecular and phenotypic analyses reveal association of diverse Colletotrichum acutatum groups and a low level of C. gloeosporioides with olive anthracnose. Applied and Environmental Microbiology, Vol. 71, pp. 2987-2998, 0099-2240

Vallejo, I., Carbú, M., Muñoz, F., Rebordinos, L., Cantoral, J.M. (2002). Inheritance of chromosome-length polymorphisms in the phytopathogenic ascomycete Botryotinia fuckeliana (anam. Botrytis cinerea). Mycological Research, Vol. 106, pp. 1075-1085, 0953-7562

Vallejo, I., Rebordinos, L., Collado, I.G., Cantoral, J.M. (2001). Differential behaviour of mycelial growth of several Botrytis cinerea strains on either Patchoulol- or Globulolamended media. Journal of Phytopathology, Vol. 149, pp. 113-118, 0931-1785

Vallejo, I., Santos, M., Cantoral, J.M., Collado, I.G., Rebordinos, L. (1996). Chromosomal polymorphism in Botrytis cinerea strains. Hereditas, Vol. 124, pp. 31-38, 0018-0661

White, T.J., Bruns, S.L., Taylor, J.W. (1990). Amplification and direct sequencing of fungal ribosomal RNA genes for phylogenetics, In: PCR Protocols: A Guide to Methods and Applications, Innis, M. A., Gelfand, D. H., Sninsky, J. J., and White, T. J., pp. 315, Academic Press, Inc., New York

Whitelaw-Weckert, M.A., Curtin, S.J., Huang, R., Steel, C.C., Blanchard, C.L., Roffey, P.E. (2007). Phylogenetic relationships and pathogenicity of Colletotrichum acutatum isolates from grape in subtropical Australia. Plant Pathology, Vol. 56, pp. 448-463, 1365-3059

Wilkins, M.R., Sanchez, J.C., Gooley, A.A., Appel, R.D., Humphery-Smith, I., Hochstrasser, D.F., Williams, K.L. (1995). Progress with proteome projects: why all proteins expressed by a genome should be identified and how to do it. Biotechnology $\mathcal{E}$ Genetic Engineering Reviews, Vol. 13, pp. 19-50, 0264-8725

Yang, J., - Wang, L., - Ji, X., - Feng, Y., - Li, X., - Zou, C., - Xu, J., - Ren, Y., - Mi, Q., - Wu, J., Liu, S., - Liu, Y., - Huang, X., - Wang, H., - Niu, X., - Li, J., - Liang, L., - Luo, Y., - Ji, K., - Zhou, W., - Yu, Z., - Li, G., - Liu, Y., - Li, L., - Qiao, M., - Feng, L., - Zhang, K. (2011). Genomic and Proteomic Analyses of the Fungus Arthrobotrys oligospora Provide Insights into Nematode-Trap Formation. PLoS Pathogens, Vol. 7, e1002179, 1553-7366.

Zeigler, R.S. (1998). Recombination in Magnaporte grisea. Annual review of phytpathology, Vol. 36, pp. 249-275, 0066-4286 


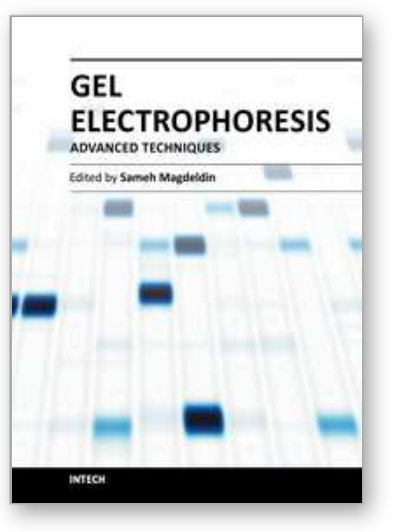

\author{
Gel Electrophoresis - Advanced Techniques \\ Edited by Dr. Sameh Magdeldin
}

ISBN 978-953-51-0457-5

Hard cover, 500 pages

Publisher InTech

Published online 04, April, 2012

Published in print edition April, 2012

As a basic concept, gel electrophoresis is a biotechnology technique in which macromolecules such as DNA, RNA or protein are fractionated according to their physical properties such as molecular weight or charge. These molecules are forced through a porous gel matrix under electric field enabling uncounted applications and uses. Delivered between your hands, a second book of this Gel electrophoresis series (Gel Electrophoresis- Advanced Techniques) covers a part, but not all, applications of this versatile technique in both medical and life science fields. We try to keep the contents of the book crisp and comprehensive, and hope that it will receive overwhelming interest and deliver benefits and valuable information to the readers.

\title{
How to reference
}

In order to correctly reference this scholarly work, feel free to copy and paste the following:

Carlos Garrido, Francisco J. Fernández-Acero, María Carbú, Victoria E. González-Rodríguez, Eva Liñeiro and Jesús M. Cantoral (2012). Molecular Microbiology Applied to the Study of Phytopathogenic Fungi, Gel Electrophoresis - Advanced Techniques, Dr. Sameh Magdeldin (Ed.), ISBN: 978-953-51-0457-5, InTech, Available from: http://www.intechopen.com/books/gel-electrophoresis-advanced-techniques/molecularmicrobiology-applied-to-the-study-of-phytopathogenic-fungi

\section{INTECH}

open science | open minds

\section{InTech Europe}

University Campus STeP Ri

Slavka Krautzeka 83/A

51000 Rijeka, Croatia

Phone: +385 (51) 770447

Fax: +385 (51) 686166

www.intechopen.com

\section{InTech China}

Unit 405, Office Block, Hotel Equatorial Shanghai

No.65, Yan An Road (West), Shanghai, 200040, China

中国上海市延安西路65号上海国际贵都大饭店办公楼 405 单元

Phone: +86-21-62489820

Fax: +86-21-62489821 
(C) 2012 The Author(s). Licensee IntechOpen. This is an open access article distributed under the terms of the Creative Commons Attribution 3.0 License, which permits unrestricted use, distribution, and reproduction in any medium, provided the original work is properly cited. 